
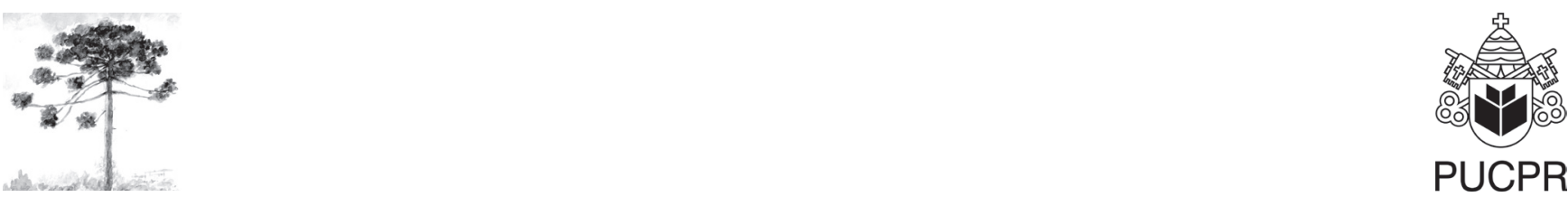

PUCPR

\title{
DIVERSIDADE E PERFIL DE RESISTÊNCIA A ANTIBI- ÓTICOS DE COLIFORMES ISOLADOS DE SALADAS COMERCIALIZADAS EM RESTAURANTES SELF-SERVICE
}

\author{
Diversity and antibiotic resistance of coliforms isolated from salads \\ commercialized in self-service restaurants
}

\section{Ana Ribeiro Junqueira ${ }^{[a]}$, Luana da Silva Sampaio ${ }^{[b]}$, Luana Rocha Fleming ${ }^{[c]}$, Janaína dos Santos Nascimento $^{[\mathrm{d}]}$}

[a] Especialização em Segurança Alimentar e Qualidade Nutricional pelo Instituto Federal de Educação, Ciência e Tecnologia do Rio de Janeiro (IFRJ), Laboratório de Microbiologia Campus Maracanã, Maracanã, RJ - Brasil.

[b] Técnica em Alimentos pelo Instituto Federal de Educação, Ciência e Tecnologia do Rio de Janeiro (IFRJ), Laboratório de Microbiologia Campus Maracanã, Maracanã, RJ - Brasil.

[c] Técnica em Biotecnologia pelo Instituto Federal de Educação, Ciência e Tecnologia do Rio de Janeiro (IFRJ), Laboratório de Microbiologia Campus Maracanã, Maracanã, RJ - Brasil.

[d] Doutora em Ciências (Microbiologia) pelo Instituto Federal de Educação, Ciência e Tecnologia do Rio de Janeiro (IFRJ), Laboratório de Microbiologia Campus Maracanã, Maracanã, RJ - Brasil, e-mail: jann.rj@uol.com.br

\section{Resumo}

A salada é um dos alimentos mais consumidos em restaurantes self-service, entretanto, pode atuar como um importante veículo de transmissão de bactérias do grupo dos coliformes. Neste trabalho, foi realizada a quantificação de coliformes presentes em saladas cruas e cozidas comercializadas em restaurantes do tipo self-service da cidade do Rio de Janeiro. Dentre as 37 amostras analisadas, 32 (83,8\%) apresentaram contagens de coliformes a $45{ }^{\circ} \mathrm{C}$ superiores ao máximo permitido pela legislação vigente. Escherichia coli foi o coliforme mais isolado, sendo encontrado em $29 \%$ das amostras analisadas, seguido por Serratia sp. e Enterobacter aerogenes. Dezenove estirpes isoladas foram submetidas à avaliação do perfil de resistência a antibióticos, e 12 delas $(63,1 \%)$ apresentaram resistência a pelo menos três antibióticos diferentes. Os resultados obtidos apontam para uma deficiência nas práticas de higiene no manuseio e/ou acondicionamento das saladas analisadas, tornando esse alimento um possível risco à saúde dos consumidores, inclusive pelo potencial de transmissão de estirpes resistentes a drogas.

Palavras-chave: Coliformes. Escherichia coli. Resistência a antibióticos. Restaurantes self-service. Contaminação de alimentos. 


\begin{abstract}
Salad is one of the most consumed foods in self-service restaurants, however, it can act as an important vehicle for the transmission of bacteria from the coliform group. In this work, we performed the quantification of coliforms in salads commercialized in self-service restaurants of Rio de Janeiro City. Amongst the 37 analyzed samples, $32\left(83.8 \%\right.$ ) had presented coliforms at $45^{\circ} \mathrm{C}$ higher than allowed by the Brazilian legislation. Escherichia coli was the most isolated coliform, being found in $29 \%$ of the analyzed samples, followed by Serratia sp. and Enterobacter cloacae. Nineteen strains were submitted to antibiotic resistance assays. Twelve of them (63.1\%) presented resistance to at least three different antibiotics. These results point to a deficiency in hygiene practices during the handling and/or the conditioning of the analyzed salads, making this food a possible risk to the health of the consumers, inclusive due potential of transmission of strains resistant to drugs.
\end{abstract}

Keywords: Coliforms. Escherichia coli. Antibiotic resistance. Self-service restaurants.

\section{INTRODUÇÃO}

Nos últimos anos, o hábito alimentar da população vem sofrendo alterações em virtude da diminuição do tempo disponível para o preparo e consumo dos alimentos. O número de pessoas que se alimenta fora de suas residências também tem crescido de modo significativo, especialmente devido à distância entre os domicílios e os locais de trabalho e à dificuldade de transporte e locomoção nos grandes centros urbanos. Assim, os estabelecimentos de preparo e comércio de alimentos assumem um papel importante na saúde pública, por causa da qualidade da alimentação da população $(2,3)$. Dentre os alimentos comumente consumidos nesses estabelecimentos, destacam-se as saladas.

Micro-organismos patogênicos e deteriorantes podem contaminar os produtos de origem vegetal por fontes diversas e essa contaminação inicia-se na fase de produção, nos campos, quando há o contato com solo, água, fezes de animais, insetos ou manipuladores, e continua durante as etapas de distribuição e comercialização $(4,5,6)$.

Além disso, muitas vezes a salada é acrescida de maionese, que é constituída, basicamente, de uma emulsão composta de azeite, ovos e vinagre. $\mathrm{O}$ vinagre pode exercer certa ação inibitória no crescimento de alguns microrganismos, porém o azeite e principalmente os ovos, comportam-se como excelentes meios de cultura, graças às suas propriedades nutritivas, constituindo um risco para a saúde quando não acondicionada corretamente $(7,8)$.
No Brasil, alguns estudos têm constatado verduras com alto grau de contaminação por enterobactérias. Alimentos como as saladas são altamente susceptíveis à contaminação por esses agentes etiológicos, destacando-se o grupo dos coliformes totais e termotolerantes.

Os coliformes totais são bactérias Gram-negativas, com a forma de bacilos, que podem ser aeróbios ou anaeróbios facultativos, e cuja principal característica que os difere das demais enterobactérias é a habilidade de fermentar lactose com produção de gás a $35^{\circ} \mathrm{C}$ em $24-48$ horas $(9,10)$. Essas bactérias fazem parte da microbiota residente do trato gastrintestinal do homem e de alguns animais, porém, a presença de coliformes totais não indica necessariamente contaminação fecal, pois esse grupo inclui diversos gêneros e espécies de bactérias não entéricas como Serratia e Aeromonas. Entretanto, a presença e a quantidade de coliformes totais são indicativos da qualidade higiênico-sanitária de um produto (11).

A definição de coliformes termotolerantes ou fecais é a mesma de coliformes totais, porém distinguindo-se os membros capazes de fermentar lactose com produção de gás em 24-48 horas à temperatura de $44,5^{\circ} \mathrm{C}$ a $45,5^{\circ} \mathrm{C}(3,12,13,14)$. Ao se pesquisar a presença de coliformes fecais em um determinado alimento, busca-se a determinação de coliformes de origem gastrintestinal, porém sabe-se que cepas de Enterobacter e Klebsiella incluídas nesse grupo podem apresentar origem não fecal (como água, solo e vegetais). Por isso, adotou-se a denominação de coliformes termotolerantes para os coliformes fecais (9). 
Diversos trabalhos confirmam que algumas estirpes de coliformes termotolerantes podem causar doenças de origem alimentar $(9,15,16,17,18)$. Um importante aspecto das infecções causadas por esses micro-organismos é a resistência aos antibióticos que são geralmente utilizados para tratar alguns tipos de infecções. Bactérias resistentes a drogas, quando ingeridas, podem ser capazes de alcançar o intestino e, através de mecanismos de transferência gênica, passar a resistência a microrganismos da flora anfibiôntica $(19,20)$. Têm-se observado que o uso indiscriminado e constante de antibióticos resulta numa pressão seletiva que contribui o aumento de resistência bacteriana, interferindo no tratamento efetivo das infecções por esses agentes (21).

Neste trabalho, buscamos estudar as condições microbiológicas de saladas comercializadas em lanchonetes e restaurantes do tipo self-service de diferentes bairros da cidade do Rio de Janeiro, através da contagem de coliformes totais e termotolerantes, destacando-se, também, a diversidade de coliformes presentes nesses alimentos e a resistência a antibióticos apresentada por algumas das estirpes isoladas.

\section{MATERIAL E MÉTODOS}

\section{Obtenção das amostras}

As amostras de saladas foram obtidas de 37 restaurantes self-service de alguns bairros da cidade do Rio de Janeiro, no período de fevereiro de 2007 a fevereiro de 2008. A coleta foi efetuada durante o horário de serviço de refeições, no horário entre $11 \mathrm{~h}$ e $13 \mathrm{~h}$. O tempo entre a aquisição das amostras e sua análise não ultrapassou 60 minutos, sendo as mesmas conduzidas imediatamente ao Laboratório de Microbiologia do Instituto Federal de Educação, Ciência e Tecnologia do Rio de Janeiro, onde foram analisadas.

\section{Número mais provável para coliformes totais e termotolerantes}

A determinação do número mais provável (NMP) de coliformes totais e termotolerantes foi realizada através da técnica de tubos múltiplos. Foi feito, inicialmente, o enriquecimento em caldo lauril sulfato triptose (LST, Isofar) a $37^{\circ} \mathrm{C}$ por 24 horas. As amostras dos tubos que apresentaram turvação e presença de gás, evidenciada em tubo de Durham invertido, foram transferidas para tubos contendo caldo verde brilhante bile $\%$ lactose (VBBL, Isofar), para determinação de coliformes totais, e para tubos contendo caldo EC (Isofar), visando à determinação de coliformes termotolerantes. Os tubos contendo caldo VBBL foram incubados a $37^{\circ} \mathrm{C}$ por $24 \mathrm{~h}$ e os tubos com caldo EC incubados em banho-maria a $45^{\circ} \mathrm{C}$ por $24 \mathrm{~h}$. Foram considerados para contagem do número mais provável os tubos que apresentaram turvação e presença de gás.

\section{Diversidade de coliformes isolados}

Buscando-se verificar a diversidade de coliformes termotolerantes presentes nas saladas analisadas, as culturas positivas presentes nos caldos VBBL e EC foram estriadas em placas contendo Ágar Eosina Azul de Metileno (EMB) e incubadas a $37^{\circ} \mathrm{C}$. Após $24 \mathrm{~h}$, as colônias crescidas foram submetidas à identificação quanto ao gênero ou espécie através de testes bioquímicos diversos, como: produção de ácidos ou acetoína (testes de VM e VP), produção de indol, motilidade, descarboxilação da lisina e arginina, utilização do citrato e malonato como fonte de carbono, fermentação de diversos açúcares, produção de $\mathrm{H}_{2} \mathrm{~S}$, de $\mathrm{CO}_{2}$ e da enzima de urease. Quando necessário, fez-se o uso do kit comercial de identificação de enterobactérias (Laborclin, Rio de Janeiro, Brasil).

\section{Determinação da resistência a antimicrobianos}

O perfil de resistência a antimicrobianos dos coliformes isolados foi identificado através da técnica de difusão de disco, conforme as recomendações do Clinical and Laboratory Standards Institute (24), empregando-se os seguintes agentes antimicrobianos fornecidos pela Sensifar (Rio de Janeiro, Brasil): ácido nalidíxico $(30 \mu \mathrm{g})$, amicacina $(30 \mu \mathrm{g})$, ampicilina (10 $\mu \mathrm{g})$, canamicina $(30 \mu \mathrm{g})$, cefalotina $(10 \mu \mathrm{g})$, cefoxitina $(30 \mu \mathrm{g})$, ciprofloxacina $(5 \mu \mathrm{g})$, cloranfenicol $(30 \mu \mathrm{g})$, estreptomicina $(10 \mu \mathrm{g})$, gentamicina $(10 \mu \mathrm{g})$, imipenem $(10 \mu \mathrm{g})$, norfloxacina $(10 \mu \mathrm{g})$ e tetraciclina $(30 \mu \mathrm{g})$.

\section{RESULTADOS E DISCUSSÃO}

As amostras foram analisadas e os valores obtidos foram comparados com os limites máximos 
permitidos para a contagem de coliformes termotolerantes (coliformes a $45^{\circ} \mathrm{C}$ ou fecais) estabelecidos pela legislação vigente no país, que classificam uma unidade amostral como aceitável ou não. Os resultados estão descritos na Tabela 1 . No caso de saladas mistas, temperadas ou não, com ou sem molho, e adicionadas ou não de maionese, o valor máximo de coliformes termotolerantes permitido pela legislação é de $10^{2} \mathrm{NMP} / g$ de produto (25).

Das 37 amostras analisadas, todas apresentavam coliformes totais, com contagens variando de
$10^{1}$ a $10^{5} \mathrm{NMP} / \mathrm{g}$ de salada. Em relação à presença de coliformes termotolerantes, apenas seis amostras $(16,2 \%)$ apresentavam contagem dentro dos padrões estabelecidos pela RDC 12 de 2001, indicando que $83,8 \%$ das saladas seriam consideradas impróprias para consumo humano.

Para avaliar a diversidade dos coliformes presentes em cada amostra de salada analisada, diferentes colônias crescidas em meio EMB foram submetidas à identificação. Dentre os coliformes isolados, E. coli foi o mais frequente, encontrado

TABELA 1 - Número mais provável de coliformes totais e termotolerantes presentes nas amostras de saladas coletadas em diferentes bairros da Cidade do Rio de Janeiro

\begin{tabular}{|c|c|c|c|}
\hline Amostra & Bairro de isolamento & Coliformes Totais ${ }^{\mathrm{a}, \mathrm{b}}$ & Coliformes termotolerantes ${ }^{a}$ \\
\hline 1 & Ilha do Fundão & $4,6 \times 10^{2}$ & $2,4 \times 10^{2}$ \\
\hline 2 & Ilha do Fundão & $>1,1 \times 10^{4}$ & $>1,1 \times 10^{4}$ \\
\hline 3 & Marechal Hermes & $>1,1 \times 10^{4}$ & $>1,1 \times 10^{4}$ \\
\hline 4 & Maracanã & $1,1 \times 10^{3}$ & $1,1 \times 10^{3}$ \\
\hline 5 & Pilares & $>1,1 \times 10^{4}$ & $>1,1 \times 10^{4}$ \\
\hline 6 & Centro & $>1,1 \times 10^{4}$ & $>1,1 \times 10^{4}$ \\
\hline 7 & Cascadura & $>1,1 \times 10^{4}$ & $>1,1 \times 10^{4}$ \\
\hline 8 & Cascadura & $>1,1 \times 10^{4}$ & $>1,1 \times 10^{4}$ \\
\hline 9 & Marechal Hermes & $1,5 \times 10^{2}$ & $3,9 \times 10^{1 \mathrm{c}}$ \\
\hline 10 & Centro & $>1,1 \times 10^{4}$ & $>1,1 \times 10^{4}$ \\
\hline 11 & Centro & $>1,1 \times 10^{4}$ & $>1,1 \times 10^{4}$ \\
\hline 12 & Centro & $>1,1 \times 10^{4}$ & $1,1 \times 10^{2}$ \\
\hline 13 & Centro & $>1,1 \times 10^{4}$ & $>1,1 \times 10^{4}$ \\
\hline 14 & Praça da Bandeira & $>1,1 \times 10^{4}$ & $>1,1 \times 10^{4}$ \\
\hline 15 & Praça da Bandeira & $2,1 \times 10^{3}$ & $2,1 \times 10^{3}$ \\
\hline 16 & Tijuca & $1,1 \times 10^{3}$ & $2,8 \times 10^{2}$ \\
\hline 17 & Tijuca & $2,1 \times 10^{2}$ & $4,0 \times 10^{1 \mathrm{c}}$ \\
\hline 18 & Tijuca & $>1,1 \times 10^{4}$ & $7,5 \times 10^{2}$ \\
\hline 19 & Tijuca & $>1,1 \times 10^{4}$ & $>1,1 \times 10^{3}$ \\
\hline 20 & Tijuca & $4,6 \times 10^{3}$ & $4,6 \times 10^{3}$ \\
\hline 21 & Vila Isabel & $2,4 \times 10^{3}$ & $3,0 \times 10^{1} \mathrm{c}$ \\
\hline 22 & Vila Isabel & $1,1 \times 10^{4}$ & $7,0 \times 10^{1 \mathrm{c}}$ \\
\hline 23 & Vila Isabel & $>1,1 \times 10^{4}$ & $1,1 \times 10^{4}$ \\
\hline 24 & Vila Isabel & $>1,1 \times 10^{4}$ & $>1,1 \times 10^{4}$ \\
\hline 25 & Centro & $>1,1 \times 10^{4}$ & $4,3 \times 10^{2}$ \\
\hline 26 & Centro & $>1,1 \times 10^{5}$ & $1,1 \times 10^{4}$ \\
\hline 27 & Tijuca & $>1,1 \times 10^{5}$ & $>1,1 \times 10^{5}$ \\
\hline 28 & Triagem & $>1,1 \times 10^{5}$ & $>1,1 \times 10^{5}$ \\
\hline 29 & Maracanã & $4,6 \times 10^{3}$ & $2,1 \times 10^{3}$ \\
\hline 30 & Tijuca & $9,2 \times 10^{1}$ & $9,2 \times 10^{1 \mathrm{c}}$ \\
\hline 31 & Tijuca & $9,2 \times 10^{1}$ & $9,2 \times 10^{1 \mathrm{c}}$ \\
\hline 32 & Tijuca & $1,1 \times 10^{4}$ & $1,1 \times 10^{4}$ \\
\hline 33 & Centro & $1,1 \times 10^{4}$ & $1,1 \times 10^{4}$ \\
\hline 34 & Centro & $>2,4 \times 10^{4}$ & $>2,4 \times 10^{4}$ \\
\hline 35 & Centro & $1,1 \times 10^{4}$ & $1,1 \times 10^{4}$ \\
\hline 36 & Centro & $1,1 \times 10^{4}$ & $1,1 \times 10^{4}$ \\
\hline 37 & Centro & $>2,4 \times 10^{4}$ & $>2,4 \times 10^{4}$ \\
\hline
\end{tabular}

Nota: ${ }^{a}$ Valores expressos em NMP/g de amostra; ${ }^{b}$ Não há limites estabelecidos pela legislação vigente para contagem de coliformes totais; ${ }^{\mathrm{c}}$ Contagens dentro do limite permitido pela legislação vigente no País para presença de coliformes a $45^{\circ} \mathrm{C}$ em saladas $\left(10^{2}\right.$ $\mathrm{NMP} / \mathrm{g}$ ). Todas as demais amostras apresentam valores superiores ao limite máximo.

Fonte: Criação do autor. 
em 29,7\% do total de amostras, seguida de Serratia sp. e Enterobacter aerogenes. Detectou-se, ainda, a presença de Klebsiella pneumoniae, K. oxytoca, Citrobacter spp., Arizona sp., E. cloacae, E. aerogenes, E. sakazakii, Hafnia alvei e Serratia sp. A frequência de isolamento dessas bactérias nas amostras analisadas encontra-se ilustrada na Figura 1. A maior parte das amostras apresentou uma ou duas espécies distintas de coliformes, sendo que a amostra 29 apresentou quatro espécies diferentes, $H$. alvei, E. aerogenes, E. cloacae e E. sakasakii. Essa última destaca-se pela sua frequência em ocasionar doenças gastrintestinais em crianças com idade inferior a dois anos.

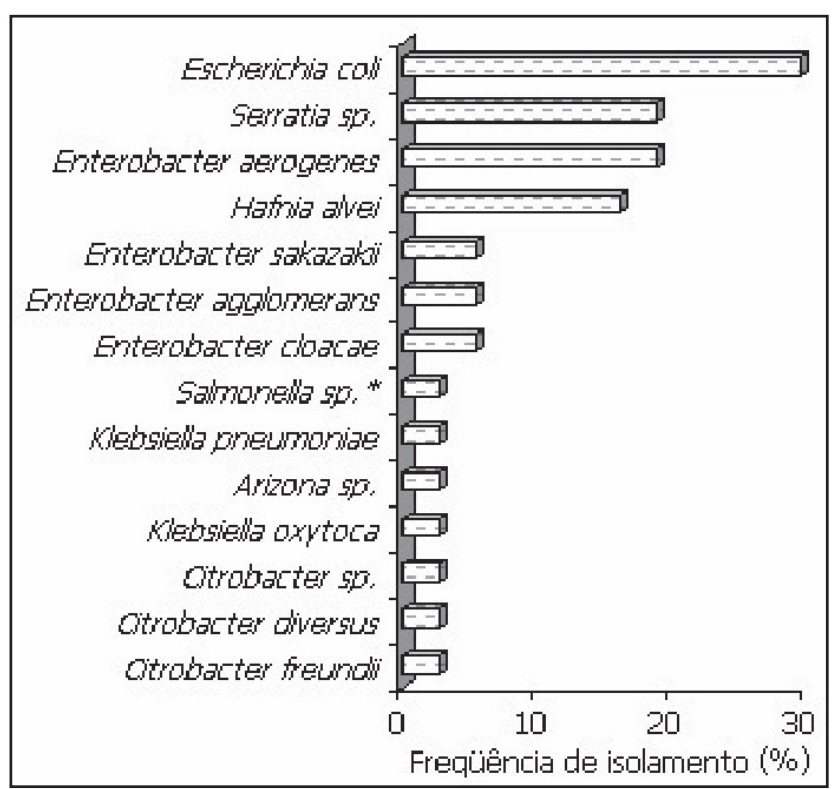

FIGURA 1 - Frequência de isolamento dos coliformes nas amostras de saladas analisadas

Nota: *Embora Salmonella não pertença ao grupo dos coliformes, sua presença foi detectada em uma das amostras analisadas.

Fonte: Criação do autor.

Os resultados de alguns testes bioquímicos para identificação de uma estirpe isolada da amostra 4 caracterizaram-na como Salmonella sp., embora esse gênero não esteja incluído no grupo dos coliformes. Essa estirpe apresentou positividade para o teste de produção de $\mathrm{H}_{2} \mathrm{~S}$, observado no meio SIM, e teste negativo para produção de urease, descartando-se a hipótese de ser uma bactéria do gênero Proteus. Testes bioquímicos adicionais, em associação com crescimento típico em meios de cultura seletivos, confirmaram a identificação dessa estirpe como Salmonella. Esse achado constitui um fato alarmante, uma vez que Salmonella é um importante patógeno causador de várias doenças associadas a alimentos, como enterite e febre tifóide, e que a legislação vigente considera impróprio para consumo qualquer alimento em que seja detectada essa bactéria.

A porcentagem elevada de amostras de saladas fora dos padrões permitidos pela legislação vigente não foi verificado apenas por nosso grupo. Nascimento e Marques (27) verificaram que das 18 amostras de saladas cruas provenientes de restaurantes self-service da cidade de São Luís, MA, analisadas, todas se encontravam fora do padrão permitido, entretanto, os autores não encontraram Salmonella em nenhuma das amostras.

Palu et al. (28) fizeram a avaliação da qualidade higiênico-sanitária de 30 amostras de hortaliças (saladas) e frutas prontas para o consumo, comercializadas em restaurantes da Cidade Universitária da Universidade Federal do Rio de Janeiro (UFRJ). Os autores detectaram que 92,3\% das amostras de hortaliças e 64,3\% das amostras de frutas estavam com contagem de coliformes fecais acima do padrão preconizado pela legislação, sendo a presença de Escherichia coli detectada em $40 \%$ do total de amostras. Diferentemente de nosso trabalho, não foi detectada a presença de Salmonella. No entanto, estudos realizados por Bricio et al. (29) e Fröder et al. (30) detectaram, além de índices de coliformes termotolerantes superiores ao permitido pela legislação em mais de $70 \%$ das amostras de saladas analisadas, a presença de Salmonella, cuja frequência de isolamento foi de 3\% do total de amostras em ambos os trabalhos.

Alguns autores também relatam a contaminação de saladas e hortaliças contaminadas por coliformes termotolerantes $(31,32,33,34,35)$, enfatizando o risco do consumo desses alimentos, uma vez que esses contaminantes fecais podem causar gastrenterites.

Comoobjetivodeinvestigarseos coliformes encontrados neste trabalho também apresentam resistência a antibióticos, 19 estirpes isoladas das amostras de saladas analisadas foram submetidas ao antibiograma. Os resultados estão apresentados na Tabela 2. Doze estirpes (63,1\%) apresentaram resistência a pelo menos três antibióticos testados, sendo consideradas então multirresistentes, o que constitui um perfil comumente encontrado em amostras clínicas. 
TABELA 2 - Perfil de resistência a antibióticos apresentado por algumas estirpes de coliformes isoladas de saladas

\begin{tabular}{llll}
\hline Estirpe & Amostra de origem & \multicolumn{1}{c}{ Identificação } & \multicolumn{1}{c}{ Perfil de resistência } \\
\hline EB01 & S04 & E. aerogenes & AMP, CFL, CLO, KAN \\
EB02 & S04 & K. terrigena & AMP \\
EB03 & S05 & E. aerogenes & AMP, CFL, TET \\
EB04 & S05 & E. aerogenes & AMP, NAL \\
EB05 & S05 & E. coli & AMI, KAN, STR \\
EB06 & S05 & Serratia sp. & AMP, CFL, STR, TET \\
EB08 & S06 & Serratia sp. & AMP, CFL, TET \\
EB09 & S06 & K. terrigena & AMP \\
EB10 & S06 & S. enteritidis & AMI, AMP, CFL, GEN \\
EB11 & S06 & H. alvei & AMP, CFL, TET \\
EB12 & K01 & K. ozaenae & AMP, GEN, KAN, NAL \\
EB13 & S01 & K. terrigena & AMP, GEN, KAN, NAL \\
EB14 & S02 & K. ozaenae & AMP \\
EB15 & S03 & H. alvei & CFL, CTX \\
EB16 & S03 & Serratia sp. & AMP, CFL, CLO, GEN, IMI, TET \\
EB19 & S04 & Serratia sp. & KAN, NAL, CLO \\
EB20 & E. coli & AMP, CFL \\
EB21 & S08 & E. coli & AMP, CFL, TET \\
EB22 & S07 & H. alvei & AMP, CFL \\
\hline
\end{tabular}

Nota: *Apesar de Salmonella enteritidis (estirpe EB10) não pertencer ao grupo dos coliformes, ela foi incluída nesses testes. AMI, amicacina; AMP, ampicilina; CFL, cefalotina; CTX, cefotaxima; CLO, cloranfenicol; CIP, ciprofloxacina; GEN, gentamicina; IMI, imipenema; KAN, canamicina; NAL, ácido nalidíxico; NOR, norfloxacina; STR, estreptomicina; TET, tetraciclina.

Fonte: Criação do autor.

Nossos resultados condizem com os encontrados por Nascimento etal. (36), que também isolaram enterobactérias resistentes a antibióticos oriundas de saladas, na cidade de São Luiz, Maranhão, evidenciando assim que no caso de infecções graves ocorridas pelas bactérias isoladas, o tratamento com alguns antibióticos seria ineficaz.

Outros trabalhos fora do Brasil também destacam o fato de que vários desses enteropatógenos isolados de saladas e que exibem resistência múltipla a antibióticos podem desempenhar um relevante papel nas infecções hospitalares e outras infecções extraintestinais, podendo ainda transmitir essa resistência com facilidade para a microbiota anfibiôntica $(5,37,38)$.

Este trabalho, portanto, confirma que as saladas comercializadas em restaurantes self-service estudadas por nosso grupo constituem um veículo de transmissão de coliformes e outras enterobactérias, incluindo estirpes resistentes a antibióticos. Considerando a elevada frequência de contaminação por microrganismos de origem fecal e o potencial risco de veiculação de doenças associadas a alimentos, sugerimos o fortalecimento do sistema de vigilância sanitária para fiscalização de alimentos oferecidos à população e de seus lugares de comercialização.

\section{AGRADECIMENTOS}

À Fundação de Amparo à Pesquisa do Estado do Rio de Janeiro (FAPERJ) e ao Edital Prociência do IFRJ, pelos auxílios financeiros concedidos ao projeto.

\section{REFERÊNCIAS}

1. Sanches AC. Avaliação do desenvolvimento microbiano em superfícies de manipulação de alimentos. Rev Hig Alim. 2007;2(154):30-3.

2. Germano PML, Germano MIS. Higiene e vigilância sanitária de alimentos. São Paulo: Varela; 2001.

3. Silva Junior EA. Manual de controle higiênico-sanitário em alimentos. 5a ed. São Paulo: Varela; 2002. 
4. Souza ML, Bezerra DCF, Furtado CM. Avaliação higiênico-sanitária de alfaces (Lactuca sativa) cultivadas pelos processos convencional e hidropônico e comercializadas em Rio Branco, AC. Rev Hig Alim. 2006;20(145):92-100.

5. Warmińska-Radyko I, Łaniewska-Trokenheim L, Miks M. Microbiological contamination of vegetable salads. Pol J Nat Sci. 2007;22(4):733-41.

6. Valentin-Bon I, Jacobson A, Monday SR, Feng PCH. Microbiological Quality of Bagged Cut Spinach and Lettuce Mixes. Appl Environ Microbiol. 2008;74(4):1240-2.

7. Furlanetto SMP, Lacerda AA, Cerqueira-Campos ML. Pesquisa de alguns microrganismos em saladas com maionese adquiridas em restaurantes lanchonetes e “rotisseries". Rev Saude Publ. 1982;16(6):307-16.

8. Bornemeier VL. Albrecht JA, Sumner SS. Survey of mayonnaise-salads for microbial safety and quality. Food Protect Trends. 2003;23(5):387-92.

9. Forsythe SJ. Microbiologia da segurança alimentar. Porto Alegre: Artmed; 2002.

10. Madigan MT, Martinko J, Parker J. Brock: biology of microorganisms. 10th ed. Prentice-Hall. 2004.

11. Jay JM. Microbiologia de alimentos. 6a ed. Porto Alegre: Artmed; 2005.

12. Adams MR, Moss MO. Microbiologia de los alimentos. Zaragoza: Acribia; 1997.

13. Takayanagui OM, Capuano DM, Oliveira CAD, Bergamini AMM, Okino MHT, Castro e Silva AAMC et al. Fiscalização de hortas produtoras de verduras do município de Ribeirão Preto, SP. Rev Soc Bras Med Trop. 2001;34(1):37-41.

14. Evans JA, Russel SL, James C. Microbial contamination of food refrigeration equipment. J Food Eng. 2004;62(3):225-32.

15. Franco BDGM, Landgraf FM. Microbiologia dos alimentos. São Paulo: Atheneu; 2003.

16. Silva N, Silveira NFA, Yokota F, Okazaki MM. Ocorrência de Escherichia coli O157:H7 em vegetais e resistência aos agentes de desinfecção de verduras. Cien Tecnol Alim. 2003;23(2):167-73.

17. Janda JM, Abbott SL. New Gram-negative enteropathogens: fact or fancy? Rev Med Microbiol. 2006;17:27-37.
18. Shaker R, Osaili T, Al-Omary W, Jaradat Z, Al-Zuby M. Isolation of Enterobacter sakazakii and other Enterobactersp. from food and food production environments. Food Control. 2007;18(10):1241-5.

19. White DG, McDermott PF. Emergence and Transfer of Antibacterial Resistance. J Dairy Sci. 2001;84(Suppl):E151-E5.

20. McMahon MA, Xu J, Moore JE, Blair IS, McDowelL DA. Environmental stress and antibiotic resistance in food-related pathogens. Appl Environ Microbiol. 2007;73(1):211-7.

21. Novak FR, Almeida JAG, Asensi MD, Moraes BA, Rodrigues DP. Antimicrobial resistance of coliform isolates from expressed human milk. Cad Saúde Publ. 2001;17(3):713-7.

22. APHA. Compendium of methods for the microbiological examination of foods. American Public Health Association. 6th ed. Washigton: APHA; 1995.

23. Farmer JJ, Davis BR, Hickman-Brenner FW, Mcworter A, Huntley-Carter GP, Asbury MA et al. Biochemical identification of new species and biogroups of Enterobacteriaceae isolated from clinical specimens. J Clin Microbiol. 1985;21(1):46-76.

24. Clinical and Laboratory Standards Institute - CLSI. Performance standards for antimicrobial susceptibility testing: M100-S16. Pensylvania: CLSI Wayne; 2006.

25. Brasil. Resolução RDC ANVISA/MS no 12 de 02 de janeiro de 2001. Regulamento Técnico sobre os Padrões Microbiológicos para Alimentos. Diário Oficial da União. 2001. [acesso 25 abr. 2007]. Disponível em: http://www.anvisa.gov.br/legis/ resol/12_01rdc.htm.

26. Brasil. Ministério da Agricultura Pecuária e Abastecimento. Instrução Normativa $n^{\circ}$ 62. Oficializar os Métodos Analíticos oficiais para Análises Microbiológicas para Controle de Produtos de Origem Animal e Água Secretaria de defesa Agropecuária. Diário Oficial da União. 2003. [acesso 25 abr. 2007]. Disponível em: http://extranet.agricultura.gov.br/sislegis-consulta/consultarLegislacao. do?operacao $=$ visualizar\&id $=2851$.

27. Nascimento AR, Marques CMP. Avaliação microbiológica de saladas "in natura" oferecidas em restaurantes self-service de São Luiz, MA. Rev Hig Alim. 1998;12(57):41-4. 
28. Palú AP, Tibana A, Teixeira LM, Miguel MAL, Pyrrho AS, Lopes HR. Avaliação microbiológica de frutas e hortaliças frescas servidas em restaurantes self-service privados da Universidade Federal do Rio de Janeiro. Rev Hig Alim. 2002;16(100):67-74.

29. Bricio SML, Leite SGF, Viana CM. Avaliação microbiológica de salpicão de frango e salada de maionese com ovos servidos em restaurantes self-service na cidade do Rio de Janeiro. Rev Hig Alim. 2005;19(137):90-5.

30. Fröder H, Martins CG, De Souza KL, Landgraf M, Franco BD, Destro MT. Minimally processed vegetable salads: microbial quality evaluation. J Food Protect. 2007;70(5):1277-80.

31. Cabrini KT, Siviero AR, Honório EF, Oliveira LFC, Venâncio PC. Pesquisa de coliformes totais e Escherichia coli em alfaces (Lactuca sativa) comercializadas na cidade de Limeira, São Paulo, Brasil. Rev Hig Alim. 2002;16(95):92-4.

32. Pacheco MSR, Fonseca YSK, Dias HGG, Candido VLP, Gomes AHS, Armelin JM, Bernardes R. Condições higiênico-sanitárias de verduras e legumes comercializados no CEAGESP de Sorocaba, SP. Rev Hig Alim. 2002;16(101):50-5.

33. Paula P, Rodrigues PSS, Tórtora JCO, Uchôa CMA, Farage S. Contaminação microbiológica e parasitológica em alfaces (Lactuva sativa) de restaurantes self-service de Niterói RJ. Rev Soc Bras Med Trop. 2003;36(6):535-7.

34. Azeredo GA, Conceição ML, Stamford, TLM. Qualidade higiênico-sanitária das refeições em restaurantes universitários. Rev Hig Alim. 2004;18(125):74-8.

35. Neta RXB, Holland N, Chaves KS, Damasceno FS. Análise dos perigos e pontos críticos de controle durante o preparo da alface servida no restaurante universitário da UFRN. Rev Hig Alim. 2004;18(126):36-43.

36. Nascimento AR, Mouchrek Filho JE, Mouchrek Filho VE, Martins AGLA, Marinho SC, Serra CLM, Alves, LMC. Avaliação da sensibilidade de antimicrobianos a cepas de Enterobacteriaceae isoladas de amostras de alface (Lactuca sativa) comercializadas na cidade de São Luís, MA. B. Cen Pesq Proc Alim. 2005;23:265-272.
37. Rodríguez C, Lang L, Wang A, Altendorf K, García F, Lipski A. Lettuce for human consumption collected in Costa Rica contains complex communities of culturable oxytetracycline and gentamicin-resistant bacteria. Appl Environ Microbiol. 2006;72(9):5870-6.

38. Bezanson GS, Macinnis R, Potter G, Hughes T. Presence and potential for horizontal transfer of antibiotic resistance in oxidase-positive bacteria populating raw salad vegetables. Int J Food Microbiol. 2008;127(1-2):37-42.

Recebido: 06/05/2007

Received: 05/06/2007

Aprovado: 04/12/2007

Approved: $12 / 04 / 2007$ 